\section{Discussion}

Close inquiries are always made into sudden deaths among Finnish conscripts. Reports on the circumstances and the possible clinical findings during the acute illness are generally reliable. The necropsy rate was high in conscripts $\left(93^{\circ}{ }_{0}\right)$ and also in other young men who died suddenly in 1969-70 $\left(83^{\circ}{ }_{0}\right)$. Although the validity of death certificates is often questionable in retrospective studies ${ }^{6-10}$ the high necropsy rate in this study adds to their value.

Two of the conscripts not examined at necropsy died from an unexpected and clinically spontaneous subarachnoid haemorrhage. The third died of purulent meningitis caused by Gramnegative diplococci (Neisseria meningitis). In these cases the cause of death was determined principally by clinical examination and lumbar puncture.

It was not possible to predict the disease that caused a conscript's death from findings at the initial medical examination or his use of medical services during his military service. The possibility of predicting a subarachnoid haemorrhage or an acute coronary attack was poor. On the other hand, it might have been possible in some cases to diagnose latent, potentially lethal myocarditis by relatively simple methods-for example, by taking an electrocardiogram of a conscript with an acute infection. The high incidence of sudden deaths in the third month of military service might have been due to the combined effect of infection waves and strenuous exercise; exercises at that time tended to be more strenuous than at the beginning of service. Rules about exercise-adequate training, no strenuous exercise immediately after a meal, no strenuous exercise in excessive heat, adequate pauses, etc-should be observed.

Strenuous exercise might be risky for up to two weeks after vaccination, when a latent myocardial or coronary involvement induced by vaccination may be present. A study is in progress to investigate whether any signs pointing to cardiac disease can be shown after vaccination.

\section{References}

${ }_{1}$ Moritz, A R, and Zamcheck, N, Archives of Pathology, 1946, 42, 459.

2 Boemke, F, Frankfurter Zeitschrift für Pathologie, 1947, 59, 104.

${ }^{3}$ Kuller, L, Lilienfeld, A, and Fisher, R, Fournal of the American Medical Association, 1966, 198, 158.

${ }^{4}$ Luke, J L, and Helpern, M, Archives of Pathology, 1968, 85, 10.

${ }_{5}$ Moritz, A R, and Morris, R C, Handbook of Legal Medicine. Saint Louis, Mosby, 1970.

${ }^{6}$ Mainland, D, American Heart fournal, 1953, 45, 644

7 Beadenkopf, W G, et al, fournal of Chronic Diseases, 1963, 16, 249.

${ }^{8}$ Kagan, A, et al, Bulletin of the World Health Organisation, 1967, 37, 477.

${ }^{9}$ Marshall, T K, Fournal of Forensic Sciences, 1970, 15, 28.

${ }^{10}$ Abramson, J H, Sacks, M I, and Cahana, E, Fournal of Chronic Diseases, $1971,24,417$.

\title{
Endotoxaemia and renal failure in cirrhosis and obstructive jaundice
}

\author{
S P WILKINSON, HELEN MOODIE, J D STAMATAKIS, V V KAKKAR, ROGER WILLIAMS
}

British Medical fournal, 1976, 2, 1415-1418

\begin{abstract}
Summary
An investigation into the possible role of endotoxins in the pathogenesis of renal failure in cirrhosis and obstructive jaundice showed the two to be closely related. None of the patients with cirrhosis who had endotoxaemia had other evidence of Gram-negative infection at the time of the study, and the endotoxaemia was therefore probably due to impaired hepatic clearance of toxins normally absorbed from the gastrointestinal tract. In contrast, bacteriological evidence of Gram-negative infection was found in most of the patients with obstructive jaundice and endotoxaemia.
\end{abstract}

\section{Introduction}

Renal failure eventually develops in up to $85 \%$ of patients with cirrhosis ${ }^{1}$ and in one series was the immediate cause of death in $11 \%{ }^{2}$ In many of these patients renal tubular function and structure are maintained, and the lesion is therefore often referred to as "functional renal failure." In others an acute tubular

\footnotetext{
Liver Unit and Department of Surgery, King's College Hospital and Medical School, London SE5 8RX

$S$ P WILKINSON, MB, MRCP, senior medical registrar HELEN MOODIE, BSC, research biochemist

J D STAMATAKIS, MB, FRCS, surgical research fellow

V V KAKKAR, FRCS, professor of clinical surgery

ROGER WILLIAMS, MD, FRCP, consultant physician and director of liver unit
}

necrosis is found. The necrosis may have been preceded by functional renal failure. Both varieties of renal failure may arise spontaneously or be precipitated by major bleeding or infections.

The pathogenesis of functional renal failure is generally thought to be an intense constriction of the renal and intrarenal arterial vessels. ${ }^{3}$ This has been attributed to sequestering of blood in the splanchnic venous circulation as a result of portal hypertension, so that the arterial circulation is "underfilled." But Ring-Larsen et al ${ }^{4}$ were unable to find an increase in renal blood flow after successful shunt operations in six patients with cirrhosis. Another possibility is that it is due to a circulating renal vasoconstrictor substance. Endotoxins are potent renal vasoconstrictors and we have previously shown a correlation between endotoxaemia and the occurrence of renal failure in fulminant hepatic failure. ${ }^{5}$

Renal failure is also a well-recognised complication of biliary obstruction. One mechanism for this may be an increased renal sensitivity to the effects of anoxia. ${ }^{6}$ Wardle has also suggested that endotoxaemia may be important since rats readily develop renal failure after intravenous administration of endotoxin if the bile duct has been ligated. ${ }^{7} \mathrm{He}$ has also reported a $25-75 \%$ incidence of endotoxaemia in patients with biliary obstruction, although details of renal function were not given. ${ }^{8}$

We describe here the relation between endotoxaemia and renal failure in 45 patients with cirrhosis and 12 with obstructive jaundice.

\section{Patients and methods}

CIRRHOSIS

Twenty-five of the 45 inpatients with cirrhosis had renal failure, and their plasma urea and creatinine concentrations were raised 
Clinical and biochemical data in patients with cirrhosis and renal failure

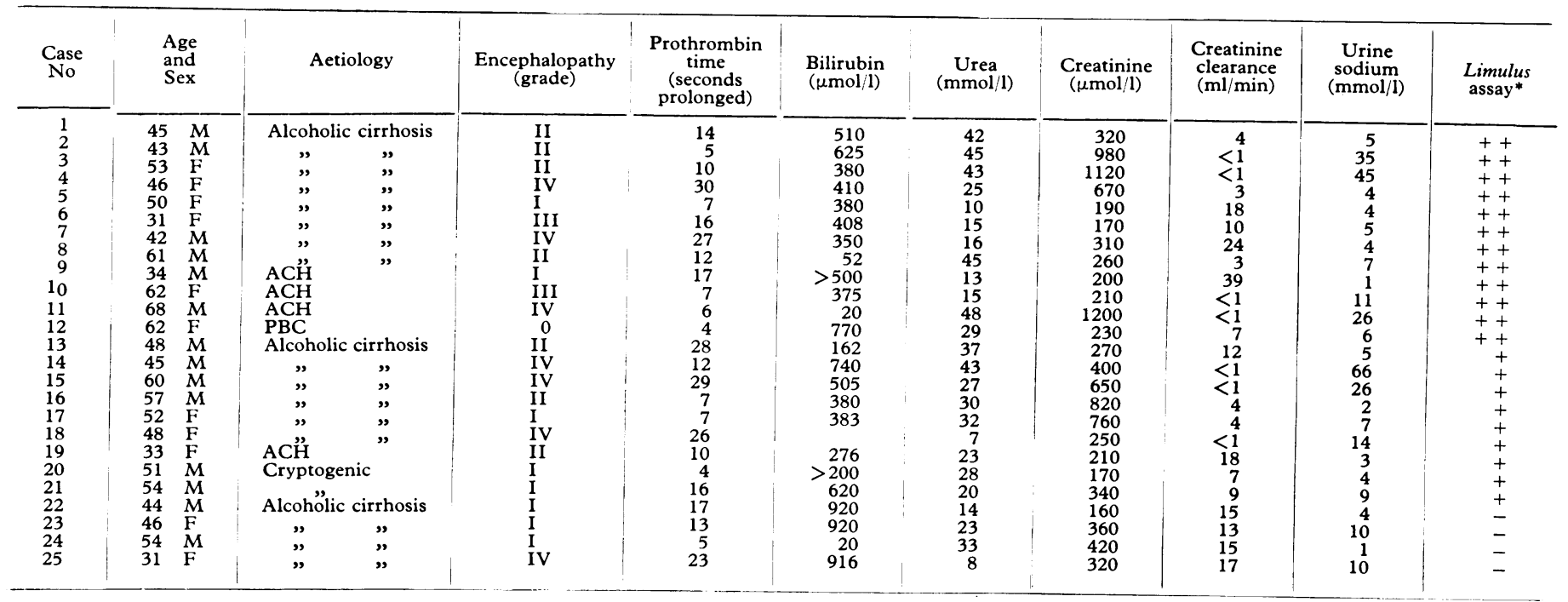

$\mathrm{ACH}=$ Active chronic hepatitis. $\mathrm{PBC}=$ Primary biliary cirrhosis.

$++=$ strongly positive; $+=$ weakly positive; $-=$ negative.

Conversion: SI to traditional units-Bilirubin: $1 \mu \mathrm{mol} / 1 \approx 0.058 \mathrm{mg} / 100 \mathrm{ml}$. Urea: $1 \mathrm{mmol} / 1 \approx 6 \mathrm{mg} / 100 \mathrm{ml}$. Creatinine: $1 \mu \mathrm{mol} / 1 \approx 0.0113 \mathrm{mg} / 100 \mathrm{ml}$.

to $48 \mathrm{mmol} / \mathrm{l}(289 \mathrm{mg} / 100 \mathrm{ml})$ and $1200 \mu \mathrm{mol} / \mathrm{l} \quad(13.6 \mathrm{mg} / 100 \mathrm{ml})$ respectively (see table). Values for endogenous creatinine clearance, based on 12- or 24-hour urine collections, ranged from 39 to $<1 \mathrm{ml} /$ min. The other 20 patients had cirrhosis of similar causes to those with renal failure (see table) and normal plasma urea and creatinine levels $(<6.7 \mathrm{mmol} / \mathrm{l}(40 \mathrm{mg} / 100 \mathrm{ml})$ and $<120 u \mathrm{~mol} / 1 \quad(1.4 \mathrm{mg}$ $100 \mathrm{ml}$ ) respectively) with no renal failure. These 20 patients had been admitted for investigation of liver disease (7 cases) and treatment of ascites (6), encephalopathy (3), or gastrointestinal haemorrhage (6, of whom 2 also had encephalopathy).

Three of the 25 patients with renal failure had evidence of a precipitating factor-namely, gastrointestinal haemorrhage in two and a laparotomy in the third. Only one patient (case 5) regained normal renal function and was discharged from hospital. In the other 24 patients the plasma urea and creatinine concentrations continued to rise until death, which occurred three days to two and a half months later. Factors contributing to death included gastrointestinal haemorrhage (16 cases), pulmonary sepsis (8), peritonitis (2), and septicaemia (2). At the time of investigation systolic arterial pressure was at least $100 \mathrm{~mm} \mathrm{Hg}$ in all patients. All but one were encephalopathic and liver function test results were invariably abnormal (see table).

Classification of renal failure-Renal failure was classified as functional or as acute tubular necrosis on the basis of a urinary sodium concentration of less than or greater than $12 \mathrm{mmol}(\mathrm{mEq}) / \mathrm{l}$ respectively. The validity of this classification has been shown by comparison with measurements of urinary lysozyme concentration, ${ }^{9}$ a specific marker of renal tubular damage. Nineteen patients had functional renal failure and the remaining six had an acute tubular necrosis.

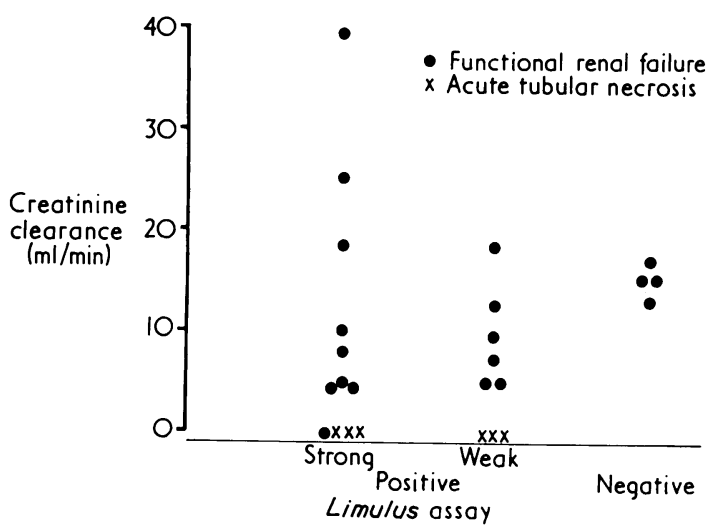

FIG 1-Results of Limulus assay related to values of creatinine clearance in patients with cirrhosis and renal failure.
Histological examination of renal tissue obtained from 15 cases a necropsy supported such a classification.

\section{OBSTRUCTIVE JAUNDICE}

Six of the 12 patients with obstructive jaundice developed renal failure, the first signs being seen preoperatively in three cases and within three days of operation in the others. Maximum recorded values for plasma urea were $26-95 \mathrm{mmol} / 1$ (157-572 $\mathrm{mg} / 100 \mathrm{ml}$ ). All six patients were deeply jaundiced (plasma bilirubin $200-560 \mu \mathrm{mol}$ $1(11 \cdot 7-32.7 \mathrm{mg} / 100 \mathrm{ml}))$. The cause of the biliary obstruction was calculi in two cases, carcinoma of the pancreas in three, and hepatic duct carcinoma in one. The four patients with carcinoma died, as did one with caluli (from an overwhelming candidal septicaemia). The other patient survived after prolonged dialysis.

The six patients without renal failure had comparable plasma bilirubin levels $(150-630 \mu \mathrm{mol} / 1 \quad(8 \cdot 8-36 \cdot 8 \mathrm{mg} / 100 \mathrm{ml}))$, and the jaundice was due to calculi in four cases and carcinoma of the pancreas in the others.

\section{LIMULUS LYSATE ASSAY}

The Limulus lysate assay was performed as described, ${ }^{5}$ and all samples were tested with the same batch of lysate. Reactions were interpreted as strongly positive (solid gel throughout), weakly positive (gel adherent only to wall of tube after inverting through $180^{\circ}$ ), or negative (no gel). For measuring the reaction $0 \cdot 1,1,2,5$, and $10 \mathrm{ng} /$ $\mathrm{ml}$ of standard Escherichia coli endotoxin (Difco 0111:B4) were added to normal plasma and gave a strongly positive reaction at a concentration of $5 \mathrm{ng} / \mathrm{ml}$ and a weakly positive one at $1 \mathrm{ng} / \mathrm{ml}$.

\section{Results \\ CIRRHOSIS}

The Limulus assay gave positive results in 21 of the 25 patients with renal failure compared with only two of the 20 with normal plasma urea and creatinine concentrations, a highly significant difference $(P<0.001)$. None of the patients with a positive reaction had clinical evidence of infection, and both urine and blood cultures were sterile at the time of investigation. The 21 patients with renal failure and a positive Limulus reaction had significantly lower values for creatinine clearance than the four with a negative reaction (mean $( \pm S E$ ) $8 \pm 2 \mathrm{ml} / \mathrm{min}$ and $15 \pm 1 \mathrm{ml} / \mathrm{min}$ respectively; $\mathrm{P}<0.001$ ), but mean values were similar in the 12 patients with strongly positive and the nine with weakly positive reactions $(9 \pm 3 \mathrm{ml} / \mathrm{min}$ and $6 \pm 2 \mathrm{ml} / \mathrm{min}$ 
respectively). The four patients with a negative reaction each had functional renal failure (fig 1). The one patient with renal failure who recovered (case 5) initially had a positive reaction, but this became negative when renal function improved. Serial assays were carried out on up to four occasions in six patients who died, and in all of these the reaction remained positive.

The two patients with a positive Limulus assay reaction but without evidence of renal failure had severe hepatic encephalopathy, and both were bleeding from gastric erosions. These were the sickest patients in the group but both eventually recovered and left hospital, and repeat assays had become negative before discharge.

No statistically significant relations between the results of the Limulus assay and either the cause of the cirrhosis or individual liver function values were found.

\section{OBSTRUCTIVE JAUNDICE}

The Limulus assay gave a strongly positive result in all of the six patients with renal failure, four of whom also had bacteriological evidence of Gram-negative infection : $E$ coli in blood cultures in three, and Klebsiella in the bile in the fourth. In the other two patients blood cultures were sterile.

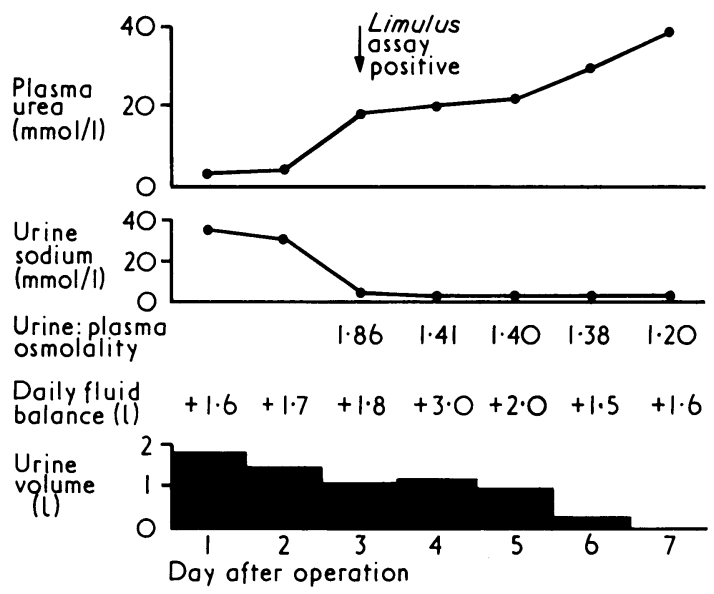

FIG 2-Development and progression of functional renal failure in patient with obstructive jaundice. Systolic arterial pressure remained above $100 \mathrm{~mm} \mathrm{Hg}$.

Conversion: SI to traditional units-Urea: $1 \mathrm{mmol} / 1 \approx$ $6 \mathrm{mg} / 100 \mathrm{ml}$. Sodium: $1 \mathrm{mmol} / 1=1 \mathrm{mEq} / 1$.

In five of the patients the renal failure had the features of acute tubular necrosis, the urine sodium concentration being over $35 \mathrm{mmol} / 1$ in all cases. In the sixth patient the urine sodium concentration was persistently below $5 \mathrm{mmol} / \mathrm{l}$, and the urine:plasma osmolality ratio was over $1 \cdot 10$, these being the features of functional renal failure. There was no evidence of fluid depletion or hypotension (fig 2).

The six patients without renal failure had a negative Limulus reaction.

\section{Discussion}

The specificity of the Limulus lysate assay for detecting endotoxin has been criticised because of the reported occurrence of false-positive reactions, in particular with Gram-positive infections ${ }^{10}$ and thrombin and thromboplastins. ${ }^{11}$ Pure growths of Gram-positive organisms have not, however, been associated with positive reactions. ${ }^{12}$ Yin has recently shown that so-called false-positives with thrombin are almost certainly due to contamination of the preparation by endotoxin since, after the thrombin had been made inactive by heat or extraction with chloroform, gelation of the Limulus lysate still occurred. ${ }^{13}$ Similar results were found with thromboplastin preparations. ${ }^{14}$

Our results show that, as in fulminant hepatic failure, there is a relation between endotoxaemia and renal failure in both cirrhosis and obstructive jaundice. Since the patients with cirrhosis showed no other evidence of Gram-negative infection, the endotoxaemia was probably due to failure of the reticuloendothelial cells of the liver to clear the endotoxins normally absorbed from the gastrointestinal tract. ${ }^{15} 16$ In contrast, the source of the endotoxaemia seemed to be a Gram-negative infection in most of the patients with obstructive jaundice, but even in this group there was no other evidence for infection in two of the patients. Bile salts prevent endotoxin absorption, ${ }^{17}$ and in obstructive jaundice these are likely to be deficient in the bowel lumen. Increased absorption of endotoxins, together with impaired hepatic clearance, ${ }^{18}$ might therefore account for the endotoxaemia seen in these two patients.

Why the assay gave a negative result in four patients with cirrhosis and renal impairment is not clear, but their values for creatinine clearance, though reduced, were significantly higher than in those with a positive reaction. Possibly the Limulus assay is not sensitive enough to detect quantities of endotoxin sufficient to cause a lesser degree of renal impairment.

The reaction of the kidney to endotoxin may vary. Early in the course of endotoxaemia there may be an increase in renal perfusion, a mechanism possibly mediated by the kallikreinbradykinin system. ${ }^{19}$ This may be a normal protective mechanism, and since patients with advanced cirrhosis often have low circulating levels of both kallikreinogen ${ }^{20}$ and bradykininogen ${ }^{21}$ they may be particularly prone to develop renal failure because its renal vasoconstrictor effects ${ }^{22}$ will be unopposed. In other clinical conditions, such as Gram-negative sepsis, endotoxininduced renal failure is often associated with acute tubular necrosis. This has been attributed to fibrin thrombi in the peritubular capillaries and glomeruli ${ }^{23}$ and has been likened to a Shwartzman-type reaction. ${ }^{19}$ Although some patients with cirrhosis in this series did have tubular necrosis, functional renal failure was commoner. Several factors might explain the relative rarity of tubular necrosis in cirrhosis. The number of heparinproducing mast cells within the glomeruli is often increased, ${ }^{24}$ and this could conceivably protect against fibrin deposition. Patients with cirrhosis also often have increased plasma fibrinolytic activity. ${ }^{25}$ In contrast, acute tubular necrosis was usually found in patients with obstructive jaundice, in whom fibrinolysis may be impaired, ${ }^{26}$ and Wardle has reported intrarenal fibrin deposition to accompany this lesion. ${ }^{8}$ Furthermore, administration of antiserum to endotoxin may protect experimental animals from the endotoxin-induced Shwartzman reaction, ${ }^{27}$ and titres to the $o$ antigen of endotoxins are often high in cirrhosis. ${ }^{28}{ }^{29}$

The finding of functional renal failure in one patient with obstructive jaundice was of particular interest, as this has not been reported. Since endotoxaemia was associated with both functional renal failure and acute tubular necrosis this may be taken as further evidence in favour of the view that these two types of failure are but part of a single spectrum of renal impairment. ${ }^{9}$

If endotoxaemia is important in the pathogenesis of the renal failure in various types of liver disease, then treatment directed against it might improve overall survival. The polymyxin antibiotics seem to have specific antiendotoxin properties, ${ }^{30}$ and the patient with cirrhosis in this series who recovered from renal failure had been treated by an intravenous infusion of polymyxin $B$ for three days. In other cases, however, we were not able to reverse renal failure with polymyxin $B$ or render the patient non-endotoxaemic as assessed by the Limulus test. Liehr $e t a l^{31}$ have also reported that the effect of polymyxin B on endotoxaemia in cirrhosis is variable. Polymyxin B is unlikely to be of any value once tubular necrosis has become established. Unfortunately, administering intestinal antibiotics, such as neomycin, is unlikely to be beneficial, as their bacteriocidal action might actually increase the release of free endotoxin.

We express our thanks to Dr E T Yin, who kindly supplied the Limulus lysate and to the department of pathology for carrying out some of the investigations reported in this paper. 


\section{References}

1 Shear, L, Kleinerman, J, and Gabuzda, G J, American fournal of Medicine, 1965, 39, 184.

2 Garceau, A J, and Chalmers, T C, New England fournal of Medicine, 1963, 268, 469.

${ }^{3}$ Epstein, M, et al, American fournal of Medicine, 1970, 49, 175.

${ }^{4}$ Ring-Larsen, H, Hesse, B, and Stigsby, B, Postgraduate Medical fournal, $1975, \mathbf{5 1}, 499$.

5 Wilkinson, S P, et al, Lancet, 1974, 1, 521.

${ }^{6}$ Dawson, J L, Annals of the Royal College of Surgeons, 1968, 42, 163.

7 Wardle, E N, and Wright, N A, British Medical fournal, 1970, 4, 472.

${ }^{8}$ Wardle, E N, Postgraduate Medical fournal, 1975, 51, 512.

9 Wilkinson, S P, et al, Postgraduate Medical fournal, 1975, 51, 503.

10 Stumacher, R J, Kovnat, M J, and McCabe, W R, New England fournal of Medicine, 1973, 288, 1261.

11 Elin, R, and Wolff, S, Fournal of Infectious Diseases, 1973, 128, 349.

12 Reinhold, R B, and Fine, J, Proceedings of the Society for Experimental Biology and Medicine, 1971, 137, 334.

13 Yin, E T, fournal of Laboratory and Clinical Medicine, 1975, 86, 430.

14 Yin, $E \mathrm{~T}$, personal communication.

15 Ravin, H, et al, fournal of Experimental Medicine, 1960, 112, 783.
16 Nolan, J P, and Ali, M V, American fournal of Digestive Diseases, 1972, 17, 161.

17 Kocsar, L T, et al, fournal of Bacteriology, 1969, 100, 220.

18 Drivas, G, James, O, and Wardle, E N, British Medical fournal, 1976, 2, 1568 .

19 Wardle, E N, Nephron, 1975, 14, 321.

${ }^{20}$ Wong, P, et al, Annals of Internal Medicine, 1972, 77, 205.

${ }^{21}$ Stewart, D, Blendis, L M, and Williams, R, fournal of Clinical Pathology, $1972,25,410$.

22 Gillenwater, J Y, Dooley, E S, and Frohlich, E D, American fournal of Physiology, 1963, 205, 293.

23 Wardle, E N, Quarterly fournal of Medicine, 1975, 174, 389.

${ }^{24}$ Devenyi, I, et al, Virchows Archiv; A: Pathogische Anatomie und Physiologie, $1968,345,238$.

25 Kwaan, H C, McFadzean, A J S, and Cook, J, Lancet, 1956, 1, 132.

26 Jedrychowski, A, et al, British Medical fournal, 1973, 1, 640.

27 Braude, I, Douglas, H, and Davis, E, Fournal of Infectious Diseases, 1973, 128, 157.

${ }^{28}$ Bjørneboe, M, Prytz, H, and $\emptyset$ rskov, F, Lancet, 1972, 1, 58.

29 Triger, D R, Alp, M H, and Wright, R, Lancet, 1972, 1, 60.

${ }^{30}$ Palmer, J D, and Rifkin, D, Surgery, Gynecology and Obstetrics, 1974, 138, 735 .

${ }^{31}$ Liehr, H, et al, Lancet, 1975, 1, 810.

\title{
Metronidazole and anaerobic sepsis
}

\author{
SUSANNAH J EYKYN， IAN PHILLIPS
}

British Medical fournal, 1976, 2, 1418-1421

\section{Summary}

Fifty patients with anaerobic sepsis were treated with intravenous and oral metronidazole. In 26 cases this was combined with other antimicrobial agents. Highly satisfactory clinical results were obtained in most patients, though in many surgical drainage was also essential. No side effects or thrombophlebitis were seen.

Mixed growths of anaerobic and aerobic bacteria were isolated from all except five patients, who produced only anaerobes. Metronidazole is the only available antimicrobial agent providing selective activity against anaerobic organisms. It is effective and safe and is usually the drug of choice for treating severe anaerobic sepsis.

\section{Introduction}

Anaerobic bacteria have always been important pathogens, but the "anaerobic renaissance" that has occurred over the past decade may probably be attributed to greatly improved laboratory techniques resulting in increased isolation of these organisms. Although isolating an anaerobe does not inevitably indicate disease, anaerobic bacteria are clearly responsible for a wide variety of infections and are particularly important in sepsis associated with the genital and intestinal tracts. Some patients with anaerobic infection can be satisfactorily treated by surgical intervention alone, but in many appropriate chemotherapy is required. The antimicrobial agents that are active against anaerobic bacteria include chloramphenicol, lincomycin, and

Department of Microbiology, St Thomas's Hospital Medical School, London SE1 7EH

SUSANNAH J EYKYN, MB, MRCPATH, senior lecturer in microbiology IAN PHILLIPS, MD, MRCPATH, professor of microbiology clindamycin, each of which may cause potentially serious toxicity. Phillips and Warren concluded that Bacteroides fragilis is usually also susceptible to sulphonamides, co-trimoxazole, and spectinomycin but there has been no clinical evaluation of the efficacy of these drugs. ${ }^{12}$

Metronidazole has been used as an oral treatment for trichomoniasis for 16 years and has proved highly effective and safe. It has also been used extensively in larger doses for giardiasis and amoebiasis. Metronidazole was first used against anaerobic infections in 1962 by Shinn ${ }^{3}$ in the treatment of acute ulcerative gingivitis, but not until 10 years later did Tally et al report its use in bacteroides infections. ${ }^{4}$ Since then many workers have shown that it is clinically effective ${ }^{5-9}$ in several types of anaerobic infection. It has also been used successfully in the chemoprophylaxis of infection after hysterectomy, ${ }^{6}$ appendicectomy, ${ }^{8}$ and elective colonic surgery. ${ }^{10}$ Until recently, however, its therapeutic use in severely ill patients, particularly those undergoing major abdominal surgery, was limited because no parenteral preparation was available, although a rectal preparation has been used successfully in some patients, largely as prophylaxis. ${ }^{78}$ An intravenous preparation of metronidazole is now avaiable, and we have reviewed the results of treating anaerobic sepsis in severely ill patients with intravenous and oral metronidazole.

\section{Patients and methods}

The decision to use metronidazole was made after consultation between clinician and microbiologist. It was mainly given for sepsis associated with the genital or intestinal tracts, gas gangrene, and anaerobic bacteraemia. The presence of putrid pus together with typical peaks of volatile fatty acids on chromatography of the pus provided excellent and immediate evidence of anaerobic sepsis. Blood counts and liver enzyme concentrations were regularly monitored in all patients receiving metronidazole, and whenever possible serum was taken for assay during treatment.

When possible metronidazole was given as the sole antimicrobial, but in many patients other agents were also given, either for co-existing infection of the respiratory tract or because it was considered clinically desirable to cover aerobic as well as anaerobic bacteria. Intravenous metronidazole was administered as a buffered, isotonic $0.5 \% \mathrm{w} / \mathrm{v}$ 